\title{
Risk analysis model in aquaponics
}

\author{
Gheorghe Adrian Zugravu, Cristian Muntenita, Ciprian Petrisor Plenovici, Constanta Laura \\ Augustin (Zugravu) \\ “Dunărea de Jos" University of Galaţi,Galati, Romania
}

\begin{abstract}
This paper about aquaponic risk analysis find to identifies the main risks in an aquaponic system and how they can be minimized. Monitoring and control of essential environmental parameters is important for maintaining a healthy and stable systemin aquaponic.
\end{abstract}

\section{Key words: aquaponiq; risk analysis;}

\section{Introduction}

Intensive beekeeping integrated with aquaponic systems is a beekeeping variant for small farmers that aims to make intensive beekeeping a viable and sustainable economic activity. Intensive beekeeping integrated with aquaponic systems is a high-tech beekeeping variant.

Aquapoponia is a food production system that combines the production of hydroponic vegetables and aquaculture into a closed recycled system. This combination of methods of production of integrated multi-trophic hydropells and aquaculture eliminates problems associated with individual production methods.

The main objectives of apiculture integrated into aquaponic systems are: simultaneous integration of technical, economic, environmental, spatial and societal objectives to the development of the model of multifunctional avaponic production platforms.

\section{Risk analysis}

According to the ISO 31000 Risk Management Standard 2009 , risk is simply "the effect of uncertainty on the objectives". Based on this definition, the phrase "everyone manages risk" is therefore true. If we accept that all individuals and organizations have goals, that these goals are necessarily set in the future and that the future is uncertain, then each and every organization manages the risk.
The risk management system provides tools to build a structured vision of the future and to address the issue of related uncertainty. Implementing risk management in an organization or regulatory body gives management the opportunity to make rational decisions based on available information, no matter how full it is. In order to prove the feasibility of implementing a risk management system, we will return to the fundamental principle of project management, which characterizes the interdependence of the following parameters: the budget, the quality of the finished product and the implementation time. Risk management tools help to make a rational choice among a number of alternatives. In other words, the level of achievement of the desired regulatory objective will depend on the cost of the preventive measures and the abandonment of the expected benefits from one or more areas of economic activity.

There are several sources of risk. To identify the risk, the project team should review the scope of the program, cost estimates, program (including critical path evaluation), technical maturity, key performance parameters, performance challenges, stakeholders' expectations of the current plan, external dependencies, and internal challenges, integration, interoperability, sustainability, supply chain vulnerabilities, threat management, cost deviations, test event expectations, safety, security, and more [2], [5].

To prevent the aquqponic risks that may arise in a particular business, we need to identify and analyze them at first.

Corresponding Author: Gheorghe Adrian Zugravu, "Dunărea de Jos” University of Galaţi,Galati, Romania, zugravuadrian@yahoo.com 
- $\quad$ Fish diseases

As in aquaculture, there is a risk of fish disease in aquapony. Fish diseases are many and can arise for various reasons, such as bacteria, viruses, parasites. Often these problems are triggered by the poor water quality or inadequate care of the aquaponic system. Fish are healthy when living in balance with their environment and potentially harmful elements in that environment.

- $\quad$ Plant pests

One of the most common problems in aquapony is that of plants that can be easily attacked by pests that in turn destroy plants.

- $\quad$ Failure to observe the water temperature control Unlike the domestic temperature of mammals that is regulated and practically stable, fish and other marine animals vary depending on the water they live in. So water temperature in aquapony is an impetus that should be taken into account to prevent problems that may arise in the future.

- The oxygen level is too low

Fish and plants need a sufficient amount of oxygen to survive. If the latter have more oxygen $(20 \%)$ in the environment they live, fish are less favored because they contain only $1 \%$ of $\mathrm{O} 2$ in water. For this reason, it is necessary to maintain in the water a quantity of oxygen that will favor the growth and the aquation of fish in the aquaponic system [8], 12].

- Unreasonable control of $\mathrm{pH}$

$\mathrm{pH}$ measures acidity or alkalinity in water. Value 7 represents neutrality; below this value, the water is acidic, and above this value is basic. For survival, fish need a $\mathrm{pH}$ of between 5 and 9 .

- $\quad$ High sodium levels

Sodium is of major importance in physical processes in the body. Fish, as well as other aquatic animals, take this mineral through the water they live in.

- Unreasonable control of electrical conductivity Water, irrespective of the source, contains, besides molecules of $\mathrm{H} 2 \mathrm{O}$ (pure water) and a lot of other substances. As we purify water, conductivity decreases. The water conductivity gives us information about its chemical composition and its ion concentration and movement.

In order to ensure an adequate living environment for fish, plants and bacteria, account must be taken of the water parameters in which aquatic species live.

\section{- Contamination of water}

Water contamination is the process of changing the composition of water. It is necessary to take the necessary measures to prevent this risk, otherwise the aquaponic products will suffer.

- $\quad$ Risk monitoring

In order to maintain optimal conditions for tilapia cultivation, the main critical parameters are kept within the following limits: ammonia (<1.5 mg / 1), nitrate
(<150 mg / 1), pH 6-8 $\left(22^{\circ} \mathrm{C}-30^{\circ} \mathrm{C}\right)$. Maintaining values hin these limits minimizes the risks in cultivation [3],[6].

- $\quad$ Fish density and pathogen control

The quality of cultivation also depends on the density of the biomass. It is kept below $50 \mathrm{~kg} / \mathrm{m} 3$ for the wellbeing of cultivation and for optimizing production [15], [17].

- $\quad$ Feeding

Fish feeding is based on the levels suggested by the fish feed producer. It is recommended that the fish be fed 4 times a day [9], [13].

- Cleaning

Tank cleaning is done manually. Through this process, it is intended to obtain up to 75 tons / year of fish, tilapia and sustainable production that is not at risk [14], [16]. It is essential to maintain good water quality for proper growth of fish and plants. The optimum environment for growing fish and vegetables is not the same. Thus, environmental parameters must be kept in an area that is optimal for the entire production system.

The optimal values for tilapia are:

- $\quad$ pH: between 7 and 8

- $\quad$ Ammonia: less than $1.5 \mathrm{mg} / 1$, preferably 0

- $\quad$ Nitrates: less than $150 \mathrm{mg} / 1$

- $\quad$ Oxygen: over 5 ppm [1], [5].

Vegetables require a pH between 6 and 7, ammonia is not harmful, and generally nitrates should be above 150 $\mathrm{mg} / \mathrm{1}$. Only micro nutrient that is not in sufficient quantity is iron, which at some point of cultivation needs to be added to the water so that the vegetables do not have a yellowish color. On the other hand, bacteria need a $\mathrm{pH}$ between 8 and 9 for optimal nitrification [7], [10]. Seeing all this, the risks we find in the system can be located in 3 different processes, which are:

\begin{tabular}{ll} 
- & Aquaculture \\
- & Bacterial nitrification \\
- & Cultivation of plants \\
\hline & Risks in the nitrification process
\end{tabular}

The nitrification process, the conversion of ammonium into nitrate, is necessary to maintain a healthy aquaponium environment. Nitrification releases hydrogen ions, thus reducing $\mathrm{pH}$. Therefore, it is necessary to include a buffer system, which adds carbonates and / or hydroxides, to stabilize the system.

- $\quad \mathrm{pH}$ risks

If nitrification does not work well, ammonium levels may rise above the maximum levels that negatively affect fish growth. If the fish are not in an optimal environment, they do not eat and the feed is accumulated in the mechanical filters and in the collecting tank, causing the oxygen level to drop, which is detrimental 
to both fish and plants and low $\mathrm{pH}$ values, around 6,will cause inefficiencies in the nitrification process.

- $\quad$ Risks due to feeding

Optimum feeding is essential in the system, both for maintaining a balanced and healthy system, and for achieving optimal growth rates. Reducing feeds negatively affects the growth rate of the system, while overcharging directly affects water quality (increasing organic load, ammonia and oxygen depletion) and production costs by squandering fish feed.

\section{- Wear unit risks}

This means that every day there is a high contribution of organic matter. Solid suspensions are separated by a mechanical filtration and settling system.

This installation of organic matter is called "dirt." It is very important to add effective cleaning systems and aeration in aquaponic systems to maintain good water quality [11].

\section{Results and Discussions}

The intensive beekeeping integrated with aquaponiq system risk analysis model calculate the various bioeconomic inputs and the species characteristics.

This data includes:

- Cohort growth to final grow-out;

- Mortality;

- FCR;

- Recovery rates from fish.

Other key data information includes:

- Sale price of fish and vegetables;

- Type of product (live or processed);

- Number of tanks or ponds;

- Stock density;

- Cost of feed;

- Cost of fingerlings;

- Loan size and costs;

- Risk aversion (production assumptions incorporating learning curves);

- Harvesting planning charts;

- Water cost and use.

For a business to run smoothly, the company needs to develop a business plan. The business plan is the basis for a successful business, being a planning tool and a guide for future work. Only a business can be funded on the basis of a credible business plan. This is a complex study that is being developed to start a business of modernizing technology by making investments, restructuring the business, etc.

The studies and information preceding the business plan elaboration refer to:

- the forecast of the internal and external market for the products to be obtained in the enterprise;

- ensuring the sources of financing the business;
- technological forecasts on products or product groups; - product and / or activity marketing studies, etc.

For the future business planning, formalized in the business plan, the emphasis is on product characteristics, predictable prices, product marketing and sales promotion, packaging, handling, storage and shipping aspects. It is essential to take into account consumer requirements and competition.

The drafting of the business plan involves the following steps:

- collect the necessary information;

- the processing of the information;

- a business plan is developed that must contain "key information".

Achieving goals requires substantiating selected activities and optimizing resources.

The strategy of a firm must allow it to achieve a sustainable competitive advantage in each sector of activity.

The business plan's opportunity is determined by:

- the need to highlight the overall image of the business and to highlight its "strengths", which ensures that it obtains competitive advantages by mitigating the risks generated by "critical (weak) points";

- evaluating the success of the business in progress and achieving a clear picture of the feasibility of the proposed business;

- testing proposals made prior to commencing business startups so that the manager can make changes to the plan to increase revenue and / or reduce costs;

- the need to formalize strategic objectives to act systematically to achieve them, and to attract potential business partners;

- to highlight the company's eligibility conditions for financing from budget resources and the viability of investment projects in case of access to external nonreimbursable financial resources.

The beneficiary must demonstrate that it can pay off its scheduled debts and debts, without undermining the normal course of business and generating significant income. In particular, it is necessary to have outlets for the products of the project. They must be certified by market studies and included in the business plan.

The project subject to the business plan and / or feasibility study must comply with the European Union environmental, hygiene and animal welfare rules, and the beneficiary unit (firm) must comply with national standards in terms of size and other eligibility conditions. 
The business plan addresses correlated activities of production, marketing and financial, using quantification methods and technical and economicfinancial indicators for the analysis of the previous period and for design.

The quality of the business plan depends on the quality of the concept and the effort made for its success. The success of a business plan is based on good evidence that contains sufficient information to fully analyze the business. The information from the company's recent years of activity, expressed both physically and in value, offers credibility to the projections of the business plan. Designing future results based on past experience gives the business plan a higher degree of credibility and a greater chance of success.

In the case of a new business, the design of future business should be based on correct revenue and expense budgets, industry-specific estimates and standards.

\section{Conclusions}

Aquaponic risk analysis aims to determine the economic condition of the company, its evolution in recent years and the causes that have influenced the results obtained. A good diagnostic analysis ensures choosing the optimal strategic option and the credibility of the business plan.

\section{Acknowledgment}

Project H2020-MSCA-RISE-2014 No. 645691: Researches on the potential conversion of conventional fish farms into organic by establishing a model and good practice guide.

\section{References}

[1] Addy, M.M., Kabir, F., Zhang, R., Lu, Q., Deng, X., Current, D., Griffith, R., Ma, Y., Zhou, W., Chen, P., Ruan, R., 2017. Co-cultivation of microalgae in aquaponic systems. Bioresource Technology, 245: 27-34.

[2] Adler, P.R., J.K. Harper, E.W. Wade, F. Takeda and S.T. Summerfelt, 2000. Economic analysis of an aquaponic system for the integrated production of rainbow trout and plants. International Journal of Recirculating Aquaculture. 1(1): 15-34.

[3] Bhatnagar A and P Devi, 2013. Water quality guidelines for the management of pond fish culture. International Journal of Environmental Science, 3: 6.
[4] Bosma, R.H., Lacambra, L., Landstra, Y., Perini, C., Poulie, J., Schwaner, M.J., Yin, Y., 2017. The financial feasibility of producing fish and vegetables through aquaponics. Aquacultural Engineering, 78:146-154.

[5] Francis-Floyd R, C Watson, D Petty and DB Pouder, 2009. Ammonia in aquatic systems (Univ. Florida, Dept. Fisheries Aquatic Sci., Florida Coop. Ext. Serv. FA-16), $<$ http://edis.ifas.ufl.edu/FA031>. Date of Access 01 January, 2015.

[6] Graber, A., Junge, R., 2009. Aquaponic Systems: Nutrient recycling from fish wastewater by vegetable production. Desalination, Volume 246, Issue 1:147-156.

[7] Kotzen B. and S. Appelbaum. 2010. An investigation of aquaponics using brackish water resources in the Negev Desert. Journal of Applied Aquaculture 22: 297-320.

[8] Lal R, 2013. Beyond Intensification. In: Paper presentation at the ASA, CSSA, \& SSSA international annual meetings, Tampa, Florida, USA.

[9] Liang, J.Y., Chien, Y.H., 2013. Effects of feeding frequency and photoperiod on water quality and crop production in a tilapia-water spinach raft aquaponics system. International Biodeterioration and Biodegradation, Volume 85: 693-700.

[10] Radosavljević V., M. Ćirković, D. Ljubojević, D. Jakić-Dimić, Z. Marković, J. Žutić, and V. Milićević. 2014. Searching for solutions in aquaculture: aquaponics. Arhiv veterinarske medicine 7: $71-78$.

[11] Ragnheidur Thorarinsdottir, 2015, Report on design and risk analysis D2.3 Ecoponics - Co-funded by the Eco-Innovation Initiative of the European Unuion;

[12] Rakocy, J. E., Masser, M.P., Losordo, T.M., 2006. Recirculating aquaculture tank production systems: aquaponics-integrating fish and plant culture. SRAC, Volume 454: 1-16.

[13] Rakocy, J.E., 1999. Aquaculture engineering - the status of aquaponics, part 1. Aquacult. Magaz, 25(4): 83-88.

[14] Salam, M.A., 2012, Raft Aquaponics for sustainable fish and vegetable production from high density fish pond. 5th Bi-annual Fisheries Conference and Research Fair 2012, Bangladesh 
Fisheries Research Forum, 18-19 January, 2012 at BARC, Dhaka.

[15] Shoko AP, SM Limbu, HDJ Mrosso and YD Mgaya, 2014. A comparison of diurnal dynamics of water quality parameters in Nile tilapia (Oreochromis niloticus, Linnaeus, 1758) monoculture and polyculture with African sharp tooth catfish (Clarias gariepinus, Burchell, 1822) in earthen ponds. Aquaculture Research, 6: 1-13.
[16] Tyson, R. V., Treadwell, D.D., Simonne, E.H., 2011. Opportunities and challenges to sustainability in aquaponic systems. Horttechnology, Volume 21, Issue 1: 6-13.

[17] Wongkiew, S., Hu, Z., Chandran, K., Lee, J.W., Khanal, S.K., 2017. Nitrogen transformations in aquaponic systems: A review. Aquacultural Engineering, 76:9-19. 